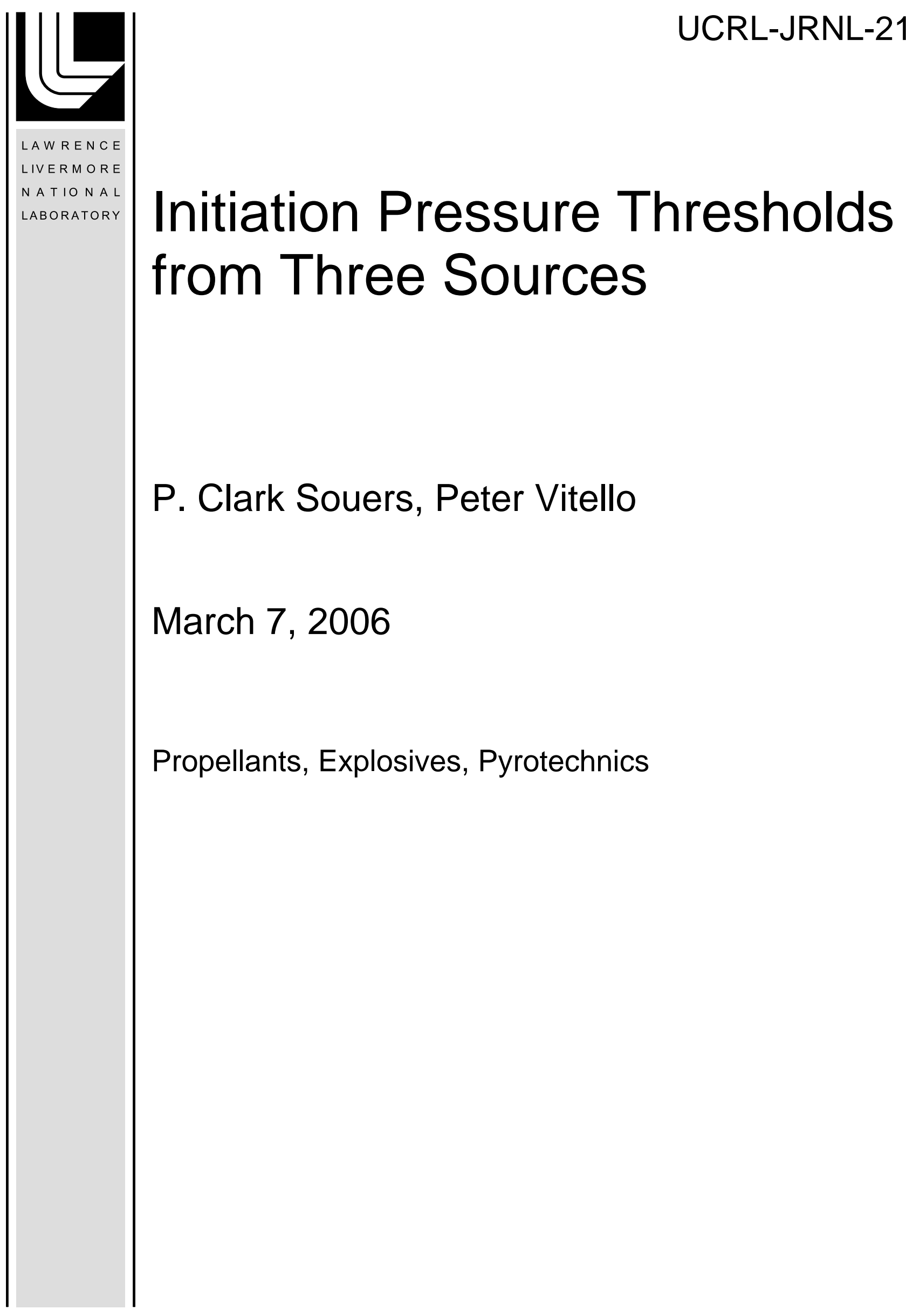


This document was prepared as an account of work sponsored by an agency of the United States Government. Neither the United States Government nor the University of California nor any of their employees, makes any warranty, express or implied, or assumes any legal liability or responsibility for the accuracy, completeness, or usefulness of any information, apparatus, product, or process disclosed, or represents that its use would not infringe privately owned rights. Reference herein to any specific commercial product, process, or service by trade name, trademark, manufacturer, or otherwise, does not necessarily constitute or imply its endorsement, recommendation, or favoring by the United States Government or the University of California. The views and opinions of authors expressed herein do not necessarily state or reflect those of the United States Government or the University of California, and shall not be used for advertising or product endorsement purposes. 


\title{
Initiation Pressure Thresholds from Three Sources
}

\section{P. Clark Souers* and Peter Vitello}

Energetic Materials Center, Lawrence Livermore National Laboratory, Livermore, CA 94550 (USA)

*Corresponding author; e-mail: souers1@1lnl.gov

\begin{abstract}
A pressure threshold is the minimum pressure needed to start explosive initiation that ends in detonation. We obtain these thresholds from three sources: 1) flyer-induced initiation gives both pressures and pulse times, and we apply a variation of the James' theory, 2) run-to-detonation times are analyzed in terms of a reaction rate to get pressure thresholds, and 3) voluminous gap test data is converted into explosive pressure thresholds. We find that small gap tests give high-pressure thresholds, which correspond to small time pulses, and vice versa. This is caused by the larger tests using longer inert spacers that produce lower pressures and flatter pulses. The very-large Eglin gap tests give thresholds comparable to the flyer results. The three sources are assembled into a much-expanded set of pressure thresholds. Generally, the thresholds increase with increasing density or increasing large amounts of binder. This kind of data is especially important for explosive models in which initiation thresholds are present. The data for TATB/LX-17/PBX 9502 fall on a single line with values of 3.1, 4.9 and $9.3 \mathrm{GPa}$ at 1.70, 1.80 and 1.90 $\mathrm{g} / \mathrm{cm}^{3}$, respectively.
\end{abstract}

Keywords: initiation, threshold, run-to-detonation, gap tests, critical energy

There is mounting evidence that a certain pressure threshold must be exceeded to start explosive initiation that ends in detonation. The traditional flyer method is represented by limited data. We here consider three sources of data and compare the results.

\section{Flyer Data}

The modern way of studying threshold initiation is to shoot a metal or plastic flyer of known thickness and velocity at an explosive. Various parameters are tried, some of which cause detonation and some do not. The flyer parameters are converted into inert explosive instant-of-impact pressures, $\mathrm{P}$, and pulse lengths, $\tau$, using impedance calculations [1]. The P- $\tau$ curves, which generally have too few points, especially at low pressures, have to be analyzed with some format, which we now consider.

Walker and Wasley defined the critical energy, $\mathrm{E}_{\mathrm{cr}}$ for threshold initiation, which is derived using [2,3]

$$
E_{c r}=P u_{p} \tau
$$

We then substitute the conservation equation

$$
P=\rho_{o} U_{S} u_{p}
$$


to get their equation

$$
E_{c r}=\frac{P^{2} \tau}{\rho_{o} U_{S}},
$$

which is the amount of energy per unit area of the flyer crossing into the explosive. Walker and Wasley hoped this would be constant for each explosive, but de Longueville experimentally showed that it was not [4].

James presented a theory, which shows an asymptotic threshold for $\mathrm{E}_{\mathrm{cr}}$, which he interprets as a trigger energy that does not affect the succeeding stages of run-to-detonation [5]. At low pressures, he defines a particle velocity-squared threshold, $u_{p o}^{2}$, given by

$$
u_{p}^{2}=\frac{E_{c r}}{\rho_{o} U_{s} \tau}+u_{p o}^{2}
$$

so that

$$
E_{c r}\left(u_{p}^{2}\right)=\rho_{o} U_{s} \tau\left(u_{p}^{2}-u_{p o}^{2}\right)
$$

We may define the corresponding pressure threshold $\mathrm{P}_{\mathrm{o}}$ from this as being

$$
P_{o}=\rho_{o} U_{s o} u_{p o}
$$

At high pressures (considerably above C-J), there is also a time threshold somewhere around $0.01 \mu \mathrm{s}$.

Because the reactive flow burn rate in our hydrocodes use a pressure ignition threshold, we try a different approach. Eq. (2) above must be true because there is a shock wave there, whether it triggers detonation or not. Eq. (3) also holds as a measure of the energy flowing through, but we can define some part of it as triggering the explosive. The critical energy becomes

$$
E_{c r}(P)=\frac{\left(P-P_{O}\right)^{2} \tau}{\rho_{O} U_{S}}
$$

which has the look of Eq. (3). This can be turned into 


$$
E_{c r}(P)=\frac{\rho_{o}}{U_{S}}\left(U_{s} u_{p}-U_{s o} u_{p o}\right)^{2} \tau,
$$

which is different from Eq. (5). We use Eq. (6) in reverse to get $u_{p o}$ as a constant.

$\mathrm{P}_{\mathrm{O}}$ is called the pressure threshold in this paper. It is, actually, the long-time, minimum pressure threshold, whereas pressure thresholds really exist on every point of the $\mathrm{P}-\tau$ curve. $\mathrm{P}_{\mathrm{o}}$ is the unique value that is entered into our code models at this time.

Table 1 lists the coefficients obtained from the data [4, 6-12] with ours and the James' methods, and there is not a lot of difference. The runs have the same flyer and explosive radii, which is $12.7 \mathrm{~mm}$ in most cases. The importance of the James theory is that: first, he establishes for good the existence of the initiation threshold, and second, he brings back the critical energy as a real constant.

Besides the usual LX-17 data [7], there is also unpublished data by LeRoy Green done in 1978 and reported here [9]. Steel sabots of $155 \mathrm{~mm}$ diameter were fired into LX-17-0 (called RX-03-BB then)

samples of nominal $1.90 \mathrm{~g} / \mathrm{cm}^{3}$ density of $152.4 \mathrm{~mm}$ diameter and $101.6 \mathrm{~mm}$ length. Manganin gauges of $0.25 \mathrm{~mm}$ thickness and $6 \mathrm{~mm}$ diameter were placed inside the LX-17 at distances of 12.7, 38.1, 63.5 and $88.9 \mathrm{~mm}$. From the observed explosion intensity, Green concluded that a $1.1 \mathrm{~mm} / \mu$ s flyer with a thickness of $36 \mathrm{~mm}$ caused a reaction that continued to build and would have detonated if the sample had been large enough. A second shot at $1.0 \mathrm{~mm} / \mu$ s with a $50.8 \mathrm{~mm}$-thick flyer caused no reaction. These may be converted to a $14.4 \mu$ s pulse at 7.5 GPa for the shot that started to react and $20.5 \mu$ s and $6.6 \mathrm{GPa}$ for the shot that did not. In Table 1, the LX-17 is reported with and without these long-time points.

\section{Run-to-Detonation Times (Pop Plots)}

Run-to-detonation experiments are done differently from flyer initiation experiments. The flyers are thin, so much so that they are bent back at the edges in flight. The run-time experiments are done with massive 25-50 mm-long sabots that do not deform and are so thick that the pressure is held constant over the entire run-to-detonation of $10-20 \mu \mathrm{s}$ length. The initiation experiments typically had $12.7 \mathrm{~mm}$ radii, which may well have affected the unmeasured run-time that followed a detonation. The run-time experiments have much larger radii so that side rarefactions have little effect on the times, which are measured with on-axis gauges. The run-time experiments are measured well above the P- $\tau 50 \%$ line and are guaranteed to detonate. Yet, when the two are plotted together, both appear to be approaching an asymptotic pressure. 
We also note that the pressure in the initiation region does not stay at the initial impact value of $\mathrm{P}_{\mathrm{i}}$ but gradually increases so that

$$
P \approx P_{i}+a t
$$

Because of the form of Eq. (7), we will write our initiation rate equation in terms of $\left(\mathrm{P}-\mathrm{P}_{\mathrm{O}}\right)^{2}$. Analytically, we must account for the slow rise in the pressure as the run-to-detonation continues, so we have

$$
\frac{d F}{d t}=G_{1}\left[\left(P_{i}-P_{O}\right)+a t\right]^{2}(1-F) .
$$

We will integrate this to a burn fraction $\mathrm{F}_{\mathrm{e}}$ and a run-to-detonation time, $\mathrm{t}_{\mathrm{e}}$. We collect the pressure terms on the right and get

$$
\frac{-\ln \left(1-F_{e}\right)}{G_{1}}-\frac{a^{2} t_{e}^{3}}{3}=\left(P_{i}-P_{o}\right)^{2} t_{e}+a\left(P_{i}-P_{o}\right) t_{e}^{2}
$$

Just as we did with critical energy, we have to set something- the left side of Eq, (11) - constant in order to continue. We calculate the right side using the data and various a and $\mathrm{P}_{\mathrm{o}}$ values until we get constant values. We also estimate that $\mathrm{a} \approx 4 \mathrm{GPa}$ from the few run-times we have done with our model on LX-17. We find that as we increase the constant $\mathrm{a}$ in the fitting process, that $\mathrm{P}_{\mathrm{o}}$ becomes constant (usually by $\mathrm{a}=4$ ) for that explosive, and this is the number we take.

\section{Gap Test Data}

The gap tests were invented at Los Alamos (LANL) as local tests to determine the sensitivity of explosives. It consists of a cylindrical donor explosive that sends a shock wave through an inert spacer material into the acceptor explosive of interest. The spacer thickness is varied from shot to shot until the $50 \%$ point of causing detonation, as determined from the results in a steel witness plate at the end of the cylinder. The geometries of the various tests are listed in Table 2 [7, 13-22]. The flyer method is at the top, and the gap tests are listed in descending order of how much they usually deviate from the flyer results. In general, the farther down, the older is the test, so that brass was the first spacer, followed by aluminum and now Lucite. As time went by, the size of the parts increased and more expensive confinement of the acceptor was added. The Air Force at Eglin AFB is currently running gap tests with the largest sizes ever used. 
In Table 2, the U. S. Navy is NSWC, SSGT means small-scale gap test and LSGT is the large scale gap test. In the lower quantity tests, MGT is the modified gap test, IHEGT is for insensitive high explosives and ELSGT is the Eglin large test before they went on to even larger ones. TLSGT is a slightly smaller LANL LSGT used only for TATB.

The early tests returned only the width of the spacer as the result. The U. S. Navy later measured the particle velocity in their spacers and determined a spacer pressure-distance calibration curve. For the modified gap test alone, they converted the spacer pressure into the inert explosive instant-of-impact pressure using impedance calculations [16]. This was not done generally across all gap data, which far exceeds in quantity the flyer data, and we do that in this report.

We took the listed spacer pressure calibration as given by the Navy and the Air Force. All the earlier tests had to be modeled to get the pressure calibration curve. The next step is to convert the spacer pressures into pressures in the unreacted explosive upon impact, as was done first for the Navy's modified gap test. We have here extended this to all the tests, using the impedance method as described in Cooper [23]. We take the spacer $\mathrm{U}_{\mathrm{s}}-\mathrm{u}_{\mathrm{p}}$ coefficients and the particle velocity to be $\mathrm{C}_{\mathrm{f}}, \mathrm{S}_{\mathrm{f}}$ and $\mathrm{u}_{\mathrm{f}}$. The same in the unreacted explosive is $\mathrm{C}_{0}, \mathrm{~S}_{1}$ and $\mathrm{u}_{\mathrm{p}}$. We know the pressure in the space material, which we convert to spacer particle velocity, $\mathrm{u}_{\mathrm{f}}$, using

$$
P(\text { spacer })=\rho_{f} C_{f} u_{f}+\rho_{f} S_{f} u_{f}^{2}
$$

In the quadratic solution for $\mathrm{u}_{\mathrm{f}}$,

$$
u_{f}=\frac{-b \pm\left(b^{2}-4 a c\right)^{1 / 2}}{2 a}
$$

$\mathrm{a}=\rho_{f} S_{1}, \mathrm{~b}=\rho_{f} C_{O}$ and $\mathrm{C}=-P$. Next we calculate the explosive pressure. At the instant of impact, these pressures are the same:

$$
P(\operatorname{explosive~})=\rho_{o} C_{o} u_{p}+\rho_{o} S_{1} u_{p}^{2}=\rho_{f} C_{f}\left(2 u_{f}-u_{p}\right)+\rho_{f} S_{f}\left(2 u_{f}-u_{p}\right)^{2} .
$$

We solve this quadratic equation using Eq. (13) where 


$$
\begin{aligned}
& a=\rho_{f} S_{f}-\rho_{o} S_{1} \\
& b=-\rho_{f} C_{f}-2 \rho_{f} S_{f}\left(2 u_{f}\right)-\rho_{o} C_{o} . \\
& c=\rho_{f} C_{f}\left(2 u_{f}\right)+\rho_{f} S_{f}\left(2 u_{f}\right)^{2}
\end{aligned}
$$

Using this, we can calculate the explosive pressure. The unreacted $\mathrm{U}_{\mathrm{s}}-\mathrm{u}_{\mathrm{p}}$ coefficients of explosives are available for the common dense ones. Many are not measured, but we use this overall estimation procedure:

$$
\begin{aligned}
& C_{O}(\mathrm{~mm} / \mu \mathrm{s}) \approx 0.44 \rho_{O}^{3} ; \quad C o \leq 2.4 \\
& C_{O}(\mathrm{~mm} / \mu \mathrm{s}) \approx 2.4 \text { high values } . \\
& S_{l}=2
\end{aligned}
$$

The results are not sensitive to small errors in these coefficients. The $\mathrm{U}_{\mathrm{s}}-\mathrm{u}_{\mathrm{p}}$ coefficients of the spacer materials are given in Table 3.

Table 4 lists comparative results where three or more gap tests were run on the same explosive in a narrow density range $[15,18,20-22,24]$. The small and large scale tests at LANL and LSGT form the most common set. The top section contains near-ideal explosives, where the calculated pressures decrease in the order

$$
\text { LANL SSGT > LANL LSGT > NSWC SSGT > NSWC LSGT. }
$$

In this sequence, from left to right, the donor radius increases and we add acceptor containment. We now more fully use the number system we have in Table 2 and plot data from all gap tests as shown in Figure 1. The ideal explosives form a continuous curve all the way, and this is the reason for the number system. The TATB data is more scattered because the NSWC SSGT has a radius close to failure, so that the size effect intrudes in this case. The high numbers of the Eglin tests are close to the flyer data and are another measurement of the pressure threshold $\mathrm{P}_{\mathrm{o}}$.

Comparison of the gap distances can be confusing, with small-scale gap distances in mm and largescale in tens of $\mathrm{mm}$. The reason lies in Figure 2, which shows the pressure in the spacers for the various tests. The bigger the donor radius and the greater the acceptor confinement, the longer is the gap distance over which the pressure is held up, so that a longer spacer is used. So, the pressure is a better comparative measure than the gap width. Another result is that the pulse times are short in small tests because the pressure falls faster, and the opposite is true for the large tests. Thus, all the pressures are thresholds on the $50 \% \mathrm{P}-\tau$ curve, but only the lowest pressure is the asymptotic threshold $\mathrm{P}_{\mathrm{o}}$ that we seek. 


\section{Pressure Threshold Summary}

Now we summarize the results most likely to give $\mathrm{P}_{\mathrm{o}}$ pressure thresholds. In Table 5, we pull together the three sources of pressure data: flyer thresholds [4, 6-12], calculated run-time values [11, 21, 25-37] and the smallest gap test pressures available $[15,18]$. There are only a few Eglin shots, so we rely for a gap tests almost completely on the NSWC LSGT. It may be seen that in many cases, the LSGT gap pressures are in agreement with whatever other data there is, so that using this is a good first move. Also, the calculated run-time values are in agreement with the rest, so that this approach appears to work.

An important trend is that the thresholds increase with density as seen in Figure 3. For TATB and TATB/up-to- $15 \%$ kel-F, the data may be fit using

$$
P_{O}(\text { TATB }, G P a)=356.35-421.36 \rho_{o}+125.63 \rho_{O}^{2}, 1.70<\rho_{o}<1.93 \mathrm{~g} / \mathrm{cm}^{3} .
$$

so we predict thresholds of $4.9 \mathrm{GPa}$ at $1.80 \mathrm{~g} / \mathrm{cm}^{3}$ and $9.3 \mathrm{GPa}$ at $1.90 \mathrm{~g} / \mathrm{cm}^{3}$. This equation currently includes LX-17 and PBX 9502, and there is no way to find any particle size or morphology effect at this time.

It also seems likely that increasing the amount of binder will also increase the threshold. The greatest single set of binder data was taken on RDX plus calcium stearate, but unfortunately, the NSWC SSGT was used [20]. These explosive pressures, shown in Figure 4, are above the $\mathrm{P}_{\mathrm{o}}$ pressure threshold but certainly show the trend.

In summary, the gap tests lie on the P- $\tau$ curves with the small tests being at low $\tau$-high $\mathrm{P}$ and the large tests at high $\tau$-low $P$. The largest tests approach $P_{0}$.

\section{Variable Flyer Areas}

A critical energy of $0.5-1 \mathrm{~J} / \mathrm{mm}^{2}$ has been found for data where the flyer and acceptor have the same radius, usually $12.7 \mathrm{~mm}$. But there is some data for which the flyer has a smaller radius [11, 38-40], and we now calculate the critical energy using Eq. 7 with estimates of $\mathrm{P}_{\mathrm{o}}$ of $1 \mathrm{GPa}$ for all the near-ideal explosives, 1.2 GPa for Comp B, 2.0 GPa for $25 \mathrm{~mm}$-radius TNT, $4.5 \mathrm{GPa}$ for $1.80 \mathrm{~g} / \mathrm{cm}^{3} \mathrm{TATB}$, and $6.0 \mathrm{GPa}$ for 1.88 g/cm ${ }^{3}$ PBX 9502. 
We shall compare the flyer radius with the failure radius, $\mathrm{R}($ fail), to the best that we know it. It would seem that the smallest flyer that gave a positive result would give the failure radius, but this is not clear. The flyer acceptor samples were all $12.7 \mathrm{~mm}$ in most cases with lengths varying from 6 to $19 \mathrm{~mm}$ [7]. The occurrence of detonation was based on light being emitted from a thin layer of aluminum silicofluoride on the back face. At the time, they believed that it took $20 \mathrm{GPa}$ to make this compound emit light, but later work showed it happens at only $2.9 \mathrm{GPa}$ [41]. The run-to-detonation distance is such that these samples probably detonated, but the 0.8 and $1.5 \mathrm{~mm}$ results for TATB are suspect. Estimates of R(fail) of $2.0 \mathrm{~mm}$ for Comp B [42] and $3.1 \mathrm{~mm}$ for PBX 9502 [43] agree with the size effect data. A value of $0.5 \mathrm{~mm}$ for LX10 seems reasonable based on PBX 9501 [21]. The others are the smallest flyer radii: $1.3 \mathrm{~mm}$ for octol, 1.5 (?) and 0.8 (?) $\mathrm{mm}$ for $1.80 \mathrm{~g} / \mathrm{cc}$ TATB, and 0.8 and $2.0 \mathrm{~mm}$ for pressed TNT from two different sources.

We set the $\mathrm{X}$-axis as being the radius ratio, $\mathrm{R}_{\mathrm{f}} / \mathrm{R}\left(\right.$ fail), where $\mathrm{R}_{\mathrm{f}}$ is the flyer radius. The results are plotted in Figure 5. We get a curve that looks like the P- $\tau$ curve with a threshold at about

$$
\frac{R_{f}}{R(\text { fail })}=1
$$

which seems reasonable, but is set up by the way we had to estimate the failure radii. The important thing is that we have critical energies becoming larger as we decrease toward failure. The result is a $\mathrm{P}-\tau$ type curve that approaches a limiting value of critical energy of $0.5-1 \mathrm{~J} / \mathrm{mm}^{2}$ at the large radius ratio.

\section{Modeling}

Our modeling confirmed the statements made above but didn't add new insights. We used a Lagrange finite-element code (closely related to CALE) with Eulerian relaxation. We used Program burn with the highest achievable zoning. We first did LX-17 at 200 zone/cm with a $1 \mathrm{~mm}$ thick aluminum flyer. We tried the flyer flat and also with a quadratic bend of edge lag/radius of 0.10 and 0.25 . The latter is the bend seen in the usual LLNL flyer, which has a 5-to-1 barrel/radius ratio [1]. All three showed rise times in the first zone of explosive of $0.015 \mu \mathrm{s}$, followed by the flat pressure plateau. This is the geometry that directly gives $\mathrm{P}_{\mathrm{o}}$ 's.

Figure 6 shows calculations for the first explosive zone in the NSWC LSGT for $1.80 \mathrm{~g} / \mathrm{cm}^{3}$ TATB. Different spacer thicknesses are tried without any regard for detonation. As we go from 5 to $50 \mathrm{~mm}$ spacer thicknesses, the peak pressures decline and the rise times increase. A $5 \mathrm{~mm}$ gap with the NSWC SSGT is also included to show that it looks similar to the LSGT $5 \mathrm{~mm}$ case. The gray circles are flyer-measured 
threshold P- $\tau$ values for the TATB. This suggests that the smaller tests have shorter pulse times and higher pressures and vice versa.

Figure 7 shows the calculated pressure versus time curves in the first explosive zone on the far side of the gap for $1.88-1.90 \mathrm{~g} / \mathrm{cm}^{3} \mathrm{LX}-17 / \mathrm{PBX} 9502$. These runs each use the $50 \%$ detonation spacer gap widths for each test. The smaller gap tests have shorter spacers, and this leads to $0.05 \mu$ s rise times and high pressure peaks which quickly decline. The large tests, which have long spacer distances, have $0.2 \mu$ s rise times followed by a lower but flat pressure plateaus. We took the calculated curves and, using an estimated $\mathrm{P}_{\mathrm{o}}$ of $8 \mathrm{GPa}$, we integrated Eq. (7) to a critical energy of $1 \mathrm{~J} / \mathrm{mm}^{2}$, which is roughly the amount needed to detonate TATB. This curve roughly shows where each gap test curve might have enough energy to detonate. As suggested above, the smaller tests do have shorter pulse times and higher pressures and vice versa.

\section{Summary}

The gap tests constitute a previously unused repository of threshold information, which becomes comparable by converting all the gap data into explosive pressures. The addition of the flyer and run-time data unifies the pressure thresholds into a large body of data. 


\section{References}

[1] A. Frank, H. Chau, R. Lee, P, Vitello and P. C. Souers, Reaction Zones in Ultrafine TATB, Propellants, Explos., Pyrotech., 2003, 28, 259-364.

[2] F. E. Walker and R. J. Wasley, Critical Energy for Shock Initiation of Heterogeneous Explosives, Explosivestoffe, 1969, 17, 9-13.

[3] P. W. Cooper, Explosives Engineering, Wiley-VCH, New York, 1996, pp. 310-312.

[4] Y. de Longueville, C. Fauquignon and H. Moulard, Initiation of Several Condensed Explosives by a Given Duration Shock Wave, Proceedings Sixth Symposium (International) on Detonation, Coronado, CA, August 24-27, 1976, pp. 105-114.

[5] H. R. James, An Extension to the Critical Energy Criterion used to predict Shock Initiation Thresholds, Propellants, Explos., Pyrotech., 1996, 21, 8-13.

[6] R. C. Weingart, R. K. Jackson, C. A. Honodel and R. S. Lee, Shock Initiation of PBX 9404 by Electrically-Driven Plates, Propellants and Explosives, 1980, 5, 158-162.

[7] C. A. Honodel, J. R. Humphrey, R. C. Weingart, R. S. Lee and P. Kramer, Shock Initiation of TATB Formulations, Proceedings Seventh Symposium (International) on Detonation, Annapolis, MD, June 16-19, 1981, pp. 425-434. The Pantex gap geometry is on p. 430.

[8] C. Belanger, P. Pelletier and J. F. Drolet, "Shock Sensitivity Study of the Curable Plastic Bonded Explosives," Proceedings Eighth Symposium (International) on Detonation, Albuquerque, NM, July 15-19, 1985, pp. 361-371.

[9] LeRoy Green, Lawrence Livermore National Laboratory, private communication, 2005.

[10] B. D. Trott and R. G. Jung, Effect of Pulse Duration on the Impact Sensitivity of Solid Explosives, Proceedings Fifth Symposium (International) on Detonation, Pasadena, CA, August 18-21, 1970, pp. 191-204.

[11] R. K. Jackson, L. G. Green, R. H. Bartlett, W. W. Hofer, P. E. Kramer, R. S. Lee, E. J. Nidick, Jr., L. L. Shaw and R. C. Weingart, Initiation and Detonation Characteristics of TATB, Proceedings Sixth Symposium International) on Detonation, Coronado, CA, August 24-27, 1976, pp. 755-765.

[12] J. P. Plotard, R. Belmas, M. Nicollet and M. Leroy, Effect of a Preshock on the Initiation of HMX, TATB and HMX/TATB Compositions, Proceedings Tenth Symposium (International) on Detonation, Boston, MA, 12-16 July, 1993, pp. 507-514.

[13] J. C. Foster, Jr., K. R. Forbes, M. E. Gunger and B. G. Craig, An Eight-Inch Diameter, Heavily Confined Card Gap Test, Proceedings Eighth Symposium (International) on Detonation, Albuquerque, NM, July 15-19, 1985, pp. 229-236. The Eglin very large geometries are on pp. 230.

[14] S. A. Aubert, G. H. Parsons, J. G. Glenn and J. L. Thoreen, Calibration and Correlation of a Modified Expanded Large Scale Gap Test with the Small Scale Gap Test and the 8-inch Gap Test, Air Force Armament Lab, Eglin AFB, FL, report AFATL-TR-89-46; ADB-137016, August, 1989). The ELSGT geometry is on pp. 2, 4, 7-9.

[15] S. A. Aubert, G. H. Parsons, J. G. Glenn and J. L. Thoreen, Gap Tests as a Method of Discriminating Shock Sensitivity, Proceedings Ninth Symposium (International) on Detonation, Portland, OR, August 28-September 1, 1989, pp. 1284-1293. The ELSGT geometry is on p. 1286. 
[16] T. P. Liddiard and J. W. Forbes, Initiation of Burning and Detonation in Cast H-6 and Cast PBXW109, Proceedings Seventh Symposium (International) on Detonation, Annapolis, MD, 16-19 June, 1981, pp. 308-314. The MGT geometry is on p. 309.

[17] J. W. Forbes, J. W. Watt and H. D. Adolf, The Insensitive High Explosives (IHE) Gap Test, Naval Surface Weapons Center, Dahlgren, VA, report NSWC TR-86-58, AD-B-111,475, July, 1986. The IHEGT geometry is on $\mathrm{p}$. A-2.

[18] D. Price, A. R. Clairmont, Jr. and J. O. Erkman, The NOL Large Scale Gap Test. III. Compilation of Unclassified Data and Supplementary Information for Interpretation of Results, Naval Ordnance Laboratory, White Oak, MD, report NOLTR 74-40, AD 780429, March, 1974. The NSWC LSGT geometry is on p. 4.

[19] D. Price and T. P. Liddiard, Jr., The Small Scale Gap Test: Calibration and Comparison with the Large Scale Gap Test, Naval Ordnance Laboratory, White Oak, MD, report NOLTR 66-87; AD487353, July, 1966. The NSWC SSGT geometry is on p. 2.

[20] J. N. Ayres, L. J. Montesi and P. J. Bauer, Small-Scale Gap Test (SSGT Data Compilation: 1959-1972. Volume I, Unclassified Explosives, Naval Ordnance Laboratory, White Oak, MD, report NOLTR 73132; AD-773743, October, 1973. The NSWC SSGT geometry is on p. 3.

[21] LASL Explosive Property Data, T. R. Gibbs and A. Popolato, eds., University of California, Berkeley, 1980. The LANL LSGT and SSGT geometries are on p. 425.

[22] M. J. Urizar, S, W. Peterson and L. C. Smith, Detonation Sensitivity Tests, Los Alamos National Laboratory, report LA-7193-MS, April, 1978. The LANL LSGT and TLSGT geometries are on p. 8.

[23] P. W. Cooper, Explosives Engineering, Wiley-VCH, New York, 1996, p. 213.

[24] P. E. Kramer, Performance and Sensitivity Testing of TATB, Mason \& Hanger-Silas Mason Co., Amarillo, TX, report HMSMP-78-59, November, 1978.

[25] J. B. Ramsay and A. Popolato, Analysis of Shock Wave and Initiation Data for Solid Explosives, Proceedings Fourth Symposium (International) on Detonation, White Oak, MD, October 12-15, 1965, pp. 233-238.

[26] Unpublished data from Kevin Vandersall, Jerry Forbes, Paul Urtiew and Frank Garcia, Lawrence Livermore National Laboratory, private communications, 2002-2005.

[27] B. D. Trott and R. G. Jung, Effect of Pulse Duration on the Impact Sensitivity of High Explosives, Proceedings Fifth Symposium (International) on Detonation, Pasadena, CA, August 18-21, 1970, pp. 191-204.

[28] J. B. Ramsay and A. Popolato, Analysis of Shock Wave and Initiation Data for Solid Explosives, Proceedings Fourth Symposium (International) on Detonation, White Oak, MD, October 12-15, 1965, pp. 233-238.

[29] M. van Thiel, Compendium of Shock Wave Data, Sections A2-B, Lawrence Livermore National Laboratory report UCRL-50108 rev. 1, vol. 2, June, 1977.

[30] D. C. Dallman and J. Wackerle, Temperature-Dependent Shock Inititation of TATB-Based Explosives, Proceedings Tenth Symposium (International) on Detonation, Boston, MA, July 12-16, 1993, pp. 130-138. 
[31] R. L. Gustavsen, S. A. Sheffield, R. R. Alcon, J. W. Forbes, C. M. Tarver and F. Garcia, Embedded Electromagnetic Gauge Measurements and Modeling of Shock Initiation in the TATB Based Explosives LX-17 and PBX 9502, Shock Compression of Condensed Matter-2001, American Institute of Physics, 2002, pp. 1019-1022.

[32] J. J. Dick, C. A. Forest, J. B. Ramsay and W. L. Seitz, The Hugoniot and Shock Sensitivity of a Plastic-Bonded TATB Explosive PBX 9502, J. Appl. Phys., 1988, 63, 4881.

[33] G. E. Seay and L. B. Seely, Jr., Initiation of a Low-Density PETN Pressing by a Plane Shock Wave, Third Symposium on Detonation, Princeton, NJ, September 26-28, 1960, pp. 562-573.

[34] D. Grief, S. H. Wood and G. D. Coley, Run to Detonation in TATB, Proceedings Eighth Symposium (International) on Detonation, Albuquerque, NM, July 15-19, 1985, pp. 380-386.

[35] J. P. Plotard, R. Belmas, M. Nicollet and M. Leroy, Effect of a Preshock on the Initiation of HMX, TATB and HMX/TATB Compositions, Proceedings Tenth Symposium (International) on Detonation, Boston, MA, 12-16 July, 1993, pp. 507-514.

[36] J. Vanpoperynghe, J. Sorel, J. Aveille and J. C. Adenis, Shock Initiation of TATB and HMX Explosive Compositions, Proceedings Eighth Symposium (International) on Detonation, Albuquerque, NM, July 15-19, 1985, pp. 892-901.

[37] D. Stirpe, J. O. Johnson and J. Wackerle, Shock Initiation of XTX-8003 and Pressed PETN, J. Appl. Phys., 1976, 41, 3884-3893.

[38] H. R. Kleinhanss, F. Lungenstrass and H. Zollner, Initiation Threshold of High Explosives in Small Flyer Plates, Proceedings Ninth Symposium (International) on Detonation, Portland, OR, August 28September 1, 1989, pp. 66-75.

[39] V. S. Zhuchenko, N. K. Moshatin and A. A. Orlov, Limiting and Critical Diameters of the Charge in the Predetonation Region, Combustion, Explosions \& Shock Waves, 1988, 24, 374-375.

[40] Robert F. Scheloske and James R. Humphrey, Recent Initiation Studies on Fine Particle TATB, fragment of an LLNL manuscript, September 14, 1979.

[41] G. H. Bloom, Flash Threshold of Shocked Aluminum Silicofluoride, Lawrence Livermore National Laboratory, Livermore, CA, report UCID-21259, November, 1987.

[42] M. E. Malin, A. W. Campbell and G. W. Mautz, Particle Size Effects in One- and Two-Component Explosives, Second ONR Symposium on Detonation, White Oak, MD, February 11, 1955, pp. 478-493.

[43] A. W. Campbell, Diameter Effect and Failure Diameter of a TATB-Based Explosive, Propellants, Explos., Pyrotech., 1984, 9, 183-187.

\section{Acknowledgement}

This work was performed under the auspices of the U.S. Department of Energy by the University of California, Lawrence Livermore National Laboratory under Contract No. W-7405-Eng-48. 
Table 1. Coefficients derived from the James $\left(\mathrm{u}_{\mathrm{p}}\right)$ theory and our pressure fit. See the text for the discussion of the two Green LX-17 points.

\begin{tabular}{lc|cc|cc|cc|}
\hline & \multirow{2}{*}{$\begin{array}{c}\text { Density } \\
\text { Explosive }\end{array}$} & \multicolumn{2}{|c|}{$\mathrm{u}_{\mathrm{po}}(\mathrm{mm} / \mu \mathrm{s})$} & \multicolumn{2}{|c|}{$\mathrm{E}_{\mathrm{cr}}\left(\mathrm{J} / \mathrm{mm}^{2}\right)$} & \multicolumn{2}{|c|}{$\mathrm{P}_{\mathrm{o}}(\mathrm{GPa})$} \\
\cline { 3 - 8 } & James & ours & James & ours & James & ours \\
\hline HMX 89.5/nylon & 1.77 & 0.2 & 0.05 & 1.2 & 1.2 & 1.0 & 0.2 \\
PBX 9404 & 1.84 & 0.37 & 0.29 & 0.3 & 0.3 & 2.1 & 1.5 \\
\hline RDX, 40-400 $\mu \mathrm{m}$ & 1.54 & 0.10 & 0.03 & 0.5 & 0.5 & 0.3 & 0.1 \\
CS-84A (RDX 86) & 1.60 & 0 & 0 & 1.0 & 1.0 & 0 & 0 \\
RDX 86/pb & 1.60 & 0.5 & 0.3 & 2.2 & 1.8 & 2.1 & 1.0 \\
Comp B & 1.72 & 0.35 & 0.29 & 1.8 & 1.2 & 1.8 & 1.4 \\
\hline PBX 9502 & 1.70 & 0.8 & 0.6 & 0.8 & 0.6 & 4.9 & 3.5 \\
TATB & 1.70 & 0.5 & 0.4 & 0.8 & 0.6 & 2.5 & 2.0 \\
PBX 9502 & 1.80 & 0.9 & 0.7 & 1.0 & 0.7 & 6.6 & 4.5 \\
TATB & 1.80 & 0.9 & 0.7 & 0.6 & 0.5 & 6.8 & 4.5 \\
PBX 9502 & 1.88 & 1.1 & 0.8 & 1.2 & 0.9 & 9.9 & 6.0 \\
T1 (TATB 94.5) & 1.89 & 1.1 & 1.0 & 1.7 & 1.0 & 10 & 8.0 \\
T2 (TATB 97) & 1.90 & 1.3 & 1.2 & 1.1 & 0.7 & 13 & 10 \\
LX-17 w Green & 1.90 & 0.85 & 1.0 & 3.1 & 1.4 & 6.9 & 8.0 \\
LX-17 w/o Green & 1.90 & 1.4 & 1.1 & 1.4 & 0.9 & 14 & 9.5 \\
T3 (TATB >97) & 1.91 & 1.5 & 1.3 & 1.5 & 1.0 & 16 & 12 \\
\hline HNAB & 1.60 & & 0 & & 0.24 & & 0 \\
HNS & 1.6 & & 0 & & 0.25 & & 0 \\
LX-13 & 1.53 & & 0 & & 0.36 & & 0 \\
NM & 1.13 & 1.6 & 1.2 & 2.5 & 1.4 & 6.9 & 6.0 \\
\hline
\end{tabular}

Table 2. Summary of gap test geometries.

\begin{tabular}{|c|c|c|c|c|c|c|c|c|}
\hline \multirow[b]{2}{*}{ No. } & \multirow[b]{2}{*}{ Lab \& test } & \multicolumn{3}{|c|}{ Donor } & \multirow[b]{2}{*}{$\begin{array}{c}\text { Length } \\
(\mathrm{mm})\end{array}$} & \multirow[b]{2}{*}{ Spacer } & \multicolumn{2}{|c|}{ Acceptor } \\
\hline & & $\begin{array}{c}\text { Radius } \\
(\mathrm{mm})\end{array}$ & Explosive & $\begin{array}{l}\text { Density } \\
\left(\mathrm{g} / \mathrm{cm}^{3}\right) \\
\end{array}$ & & & $\begin{array}{c}\text { Radius } \\
(\mathrm{mm})\end{array}$ & $\begin{array}{l}\text { Length } \\
(\mathrm{mm}) \\
\end{array}$ \\
\hline 1 & LANL SSGT & 3.81 & PBX 9407 & dense & 5.26 & Brass & 6.35 & 50.8 \\
\hline 2 & Pantex & 12.7 & LX-04 & 1.86 & 38.1 & Brass & 12.7 & 25.4 \\
\hline 3 & LANL TLSGT** & 12.7 & PBX 9205 & dense & 101.6 & Al dural & 12.7 & 101.6 \\
\hline 4 & LANL LSGT & 20.64 & PBX 9205 & dense & 101.6 & Al dural & 20.64 & 101.6 \\
\hline 5 & NSWC SSGT & $2.55^{*}$ & RDX & 1.56 & 36.3 & Lucite & 2.55 & 38.1 \\
\hline \multirow[t]{3}{*}{6} & NSWC LSGT & $25.4^{*}$ & pentolite & 1.56 & 50.8 & Lucite & 18.25 & 139.7 \\
\hline & NSWC IHEGT & $25.4^{*}$ & pentolite & 1.56 & 50.8 & Lucite & 6.35 & 50.8 \\
\hline & NSWC MGT & 25.5 & pentolite & 1.56 & 51 & Lucite & 25.5 & 12.7 \\
\hline 7 & Eglin ELSGT & $47.62^{*}$ & Comp B & 1.38 & 95.25 & Lucite & 47.62 & 279.4 \\
\hline \multirow{2}{*}{8} & Eglin 8-inch & $88.9^{*}$ & Comp B & 1.68 & 203.2 & Lucite & 88.9 & $?$ \\
\hline & $\begin{array}{l}\text { Eglin Super 8-in. } \\
\text { Flyer }\end{array}$ & $90.81^{*}$ & Comp B & 1.68 & 203.2 & Lucite & 90.81 & 406.4 \\
\hline
\end{tabular}


Table 3. Densities and $\mathrm{U}_{\mathrm{s}}-\mathrm{u}_{\mathrm{p}}$ coefficients for the gap test spacers.

\begin{tabular}{cccc}
\hline & $\begin{array}{c}\rho_{\mathrm{f}} \\
\left(\mathrm{g} / \mathrm{cm}^{3}\right)\end{array}$ & $\begin{array}{c}\mathrm{C}_{\mathrm{f}} \\
(\mathrm{mm} / \mu \mathrm{s})\end{array}$ & $\begin{array}{c}\mathrm{S}_{\mathrm{f}} \\
(\text { dimless })\end{array}$ \\
\hline Lucite & 1.182 & 2.18 & 2.088 \\
Aluminum & 2.707 & 5.39 & 1.34 \\
Brass & 8.45 & 3.726 & 1.434
\end{tabular}

Table 4. Comparison of impedance-calculated explosive pressures for $50 \%$ probability of detonation in gap tests. The top section is near-ideal; the two bottom sections are less ideal.

\begin{tabular}{|c|c|c|c|c|c|c|c|}
\hline & \multirow{3}{*}{$\begin{array}{l}\text { Density } \\
\left(\mathrm{g} / \mathrm{cm}^{3}\right)\end{array}$} & \multicolumn{6}{|c|}{ Impedance-Calculated Explosive Pressures (GPa) } \\
\hline & & LANL & LANL & NSWC & NSWC & Eglin & Eglin \\
\hline & & SSGT & LSGT & SSGT & LSGT & ELSGT & 8-inch \\
\hline Amm Picrate & $1.59-1.60$ & 12 & 6 & & 4 & & \\
\hline Amm Picrate & 1.64 & 12 & 6 & & 4 & & \\
\hline Comp A-3 & $1.61-1.62$ & 9 & 4 & & 1.5 & & \\
\hline Comp A-3 & $1.64-1.65$ & 11 & $4-5$ & & 1.7 & & \\
\hline Comp B, cast & $1.68-1.73$ & 12 & $6-7$ & & $2-5$ & 1.1 & 1.0 \\
\hline DATB & $1.70-1.71$ & 12 & 6 & 6 & 5 & & \\
\hline DATB & $1.78-1.79$ & 13 & 8 & 7 & & & \\
\hline LX-04 & $1.83-1.86$ & $11-13$ & $5-6$ & 3 & 4 & & \\
\hline PBX 9404 & $1.77-1.79$ & $9-10$ & 4 & & 4 & & \\
\hline PBX 9407 & $1.65-1.66$ & $6-7$ & 4 & & 2 & & \\
\hline PBX 9407 & $1.76-1.77$ & 10 & 5 & & 3 & & \\
\hline Pentolite, psd & $1.66-1.68$ & 9 & 2.3 & 1.4 & $1.1-1.6$ & & \\
\hline RDX & $1.72-1.73$ & 7 & 3 & 2 & & & \\
\hline Tetryl & 1.62 & 12 & 5 & 1.5 & 1.3 & & \\
\hline Tetryl & $1.68-1.69$ & $7-8$ & 3.5 & 1.6 & & & \\
\hline TNT, pressed & $1.57-1.58$ & 11 & 4.5 & 2.6 & 2.3 & 2.0 & 1.7 \\
\hline TNT, pressed & $1.62-1.65$ & 12 & $5-6$ & 3.4 & 2.9 & & \\
\hline Tritonal & $1.71-1.79$ & & 14 & & $3-7$ & 2.4 & 1.7 \\
\hline$\overline{\text { Baratol, cast }}$ & 2.6 & no det & $12-15$ & & 7 & & \\
\hline NQ & $1.61-1.63$ & no det & 17 & & $9-10$ & & \\
\hline TATB & $1.87-1.89$ & 14 & 14 & 33 & 8 & & \\
\hline Explosive & $\begin{array}{l}\text { Density } \\
\text { (g/cc) }\end{array}$ & Pantex & $\begin{array}{l}\text { LANL } \\
\text { TLSGT }\end{array}$ & & & $\begin{array}{c}\text { Eglin } \\
\text { ELSGT }\end{array}$ & $\begin{array}{l}\text { Eglin } \\
\text { 8-inch }\end{array}$ \\
\hline PBX 9502 & $1.88-1.90$ & $16-17$ & 22 & & & 8.8 & 8.2 \\
\hline
\end{tabular}


Table 5. Comparison of possible pressure thresholds from three sources: flyer, run-time and the lowest gap test, which is usually the NSWC LSGT. The asterisk indicates that the data is from the Eglin 8-inch gap test.

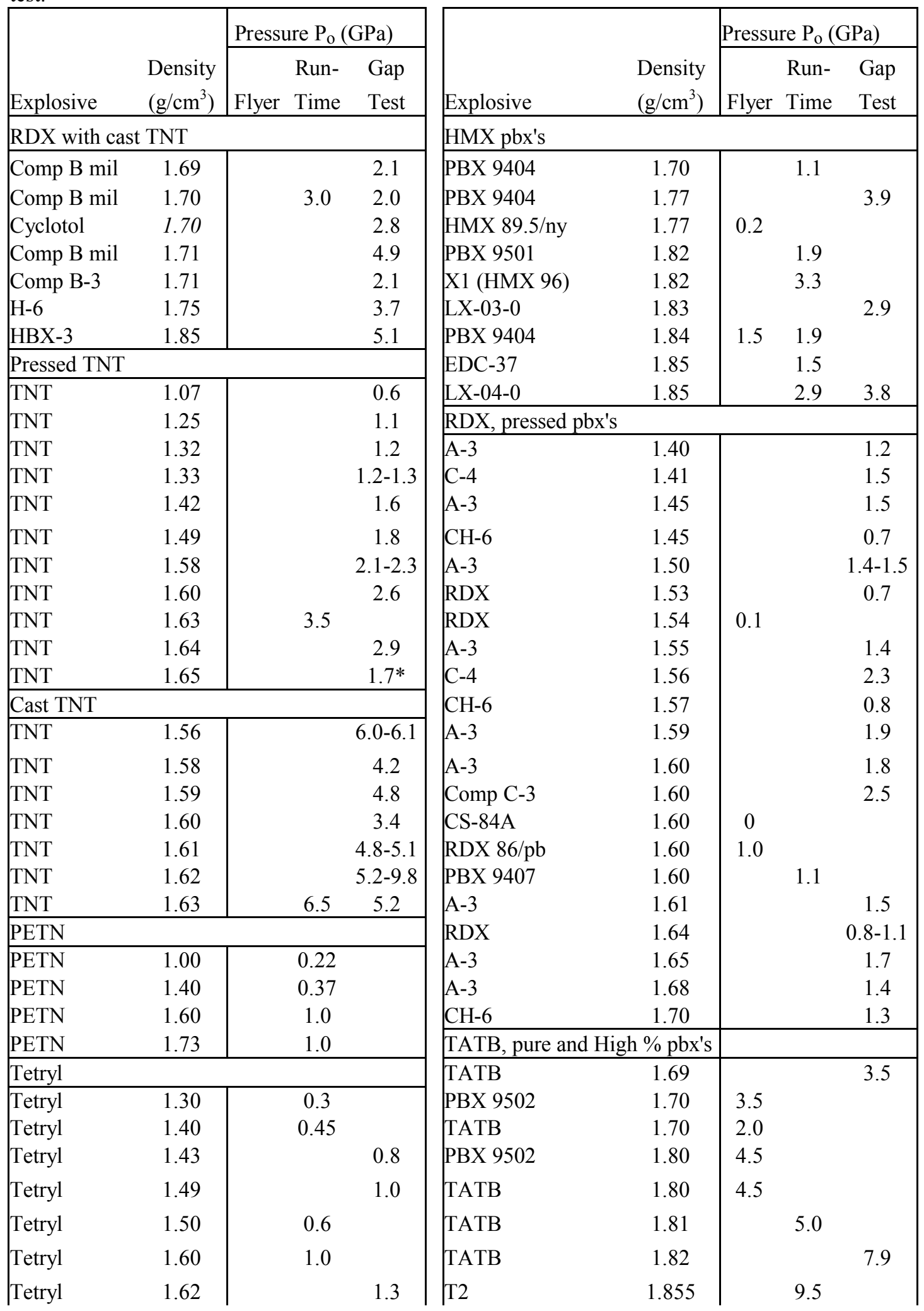




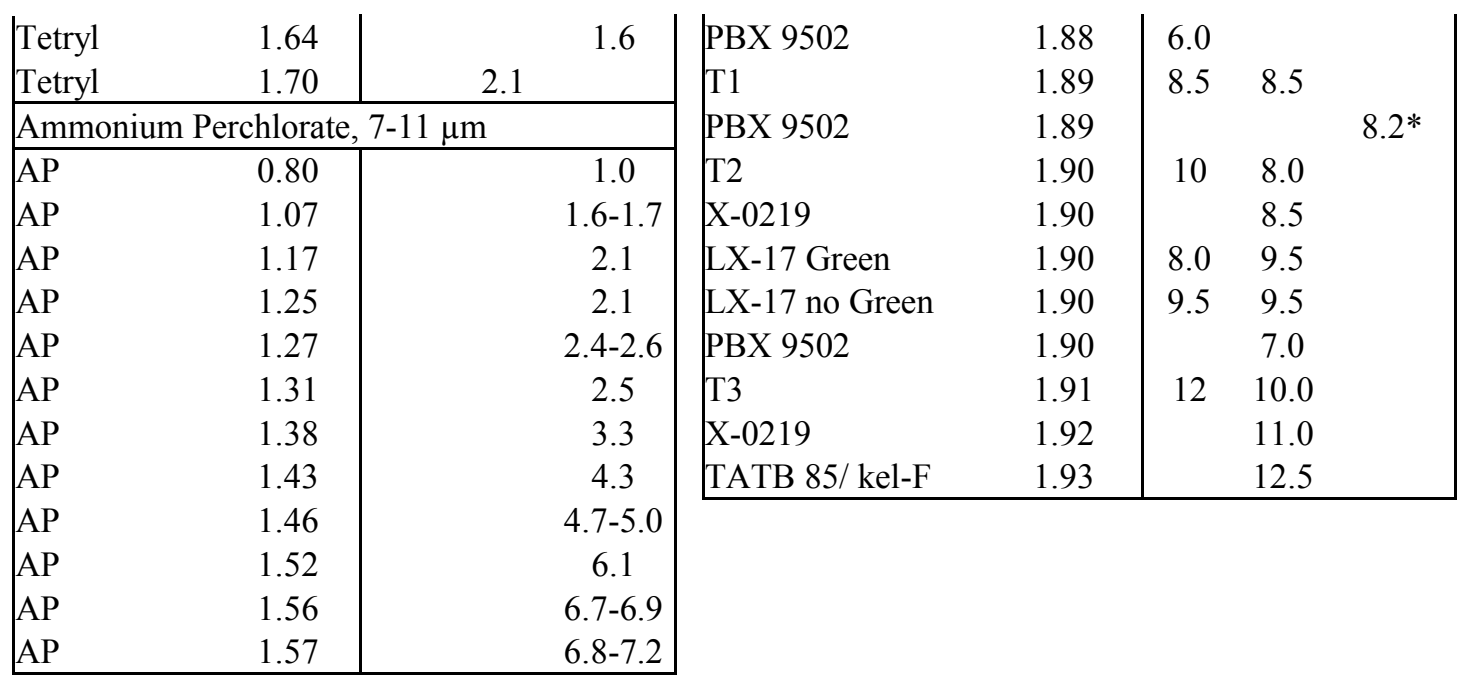




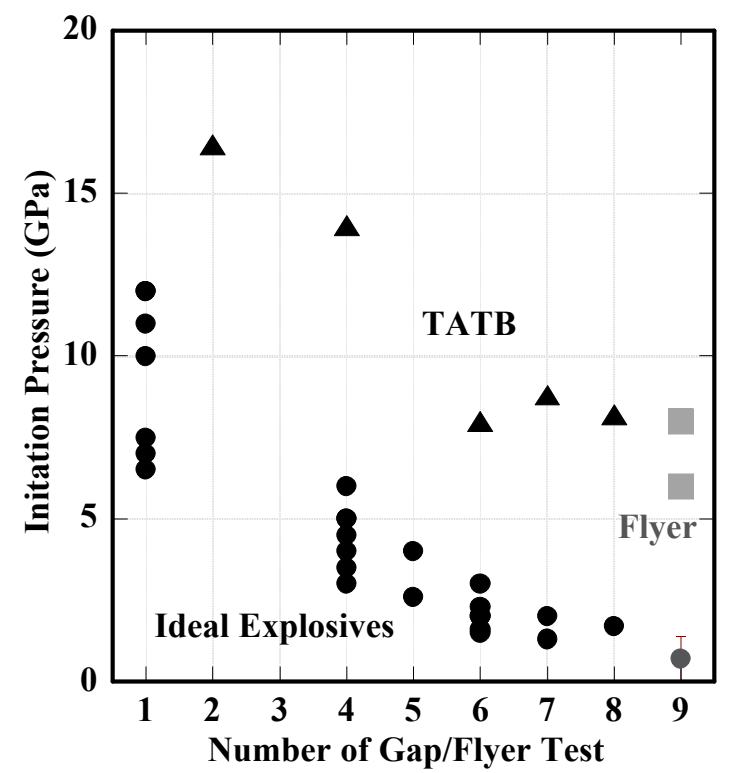

Figure 1. Initiation pressure as a function of the number of the gap test. The gap test size increases left-toright along with added confinement. Number 9 is the flyer threshold considered to be the threshold $\mathrm{P}_{\mathrm{o}}$.

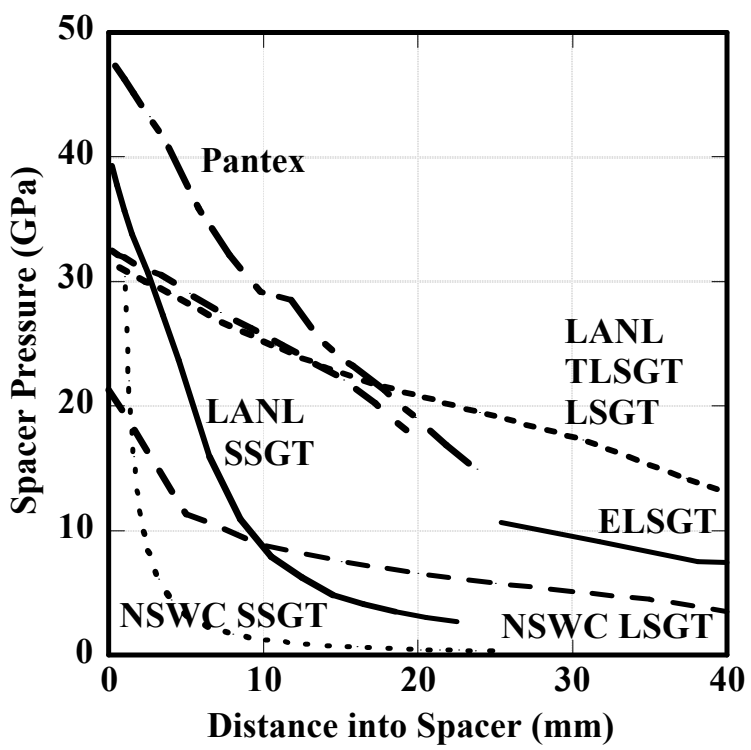

Figure 2. Pressure in the spacer material for the various gap tests. 


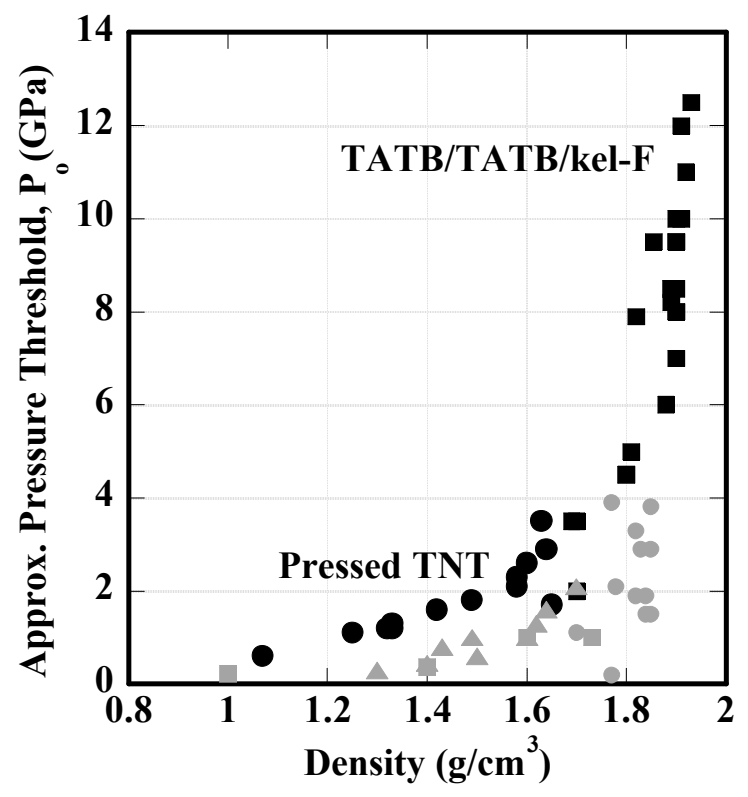

Figure 3. Pressure thresholds from all sources, $\mathrm{P}_{\mathrm{o}}$, increase as a function of density. The lower points in gray are: PETN (squares), tetryl (triangles) and HMX/RDX mixes (circles).

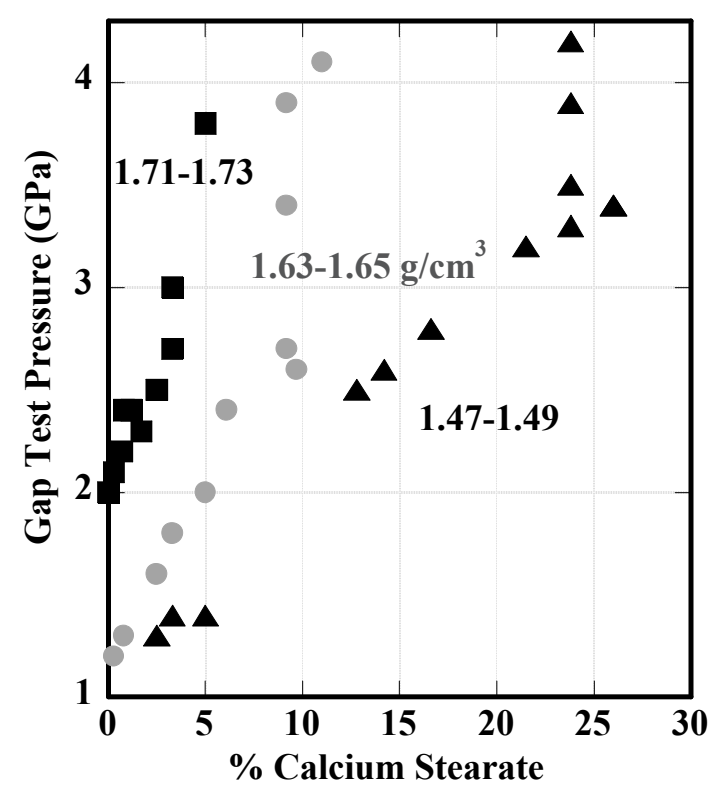

Figure 4. Impedance explosive pressures for RDX/calcium stearate mixtures run in the NSWC SSGT. Increasing either density or binder content increases the pressure. The SSGT runs are not near threshold because of the small donor radius. 


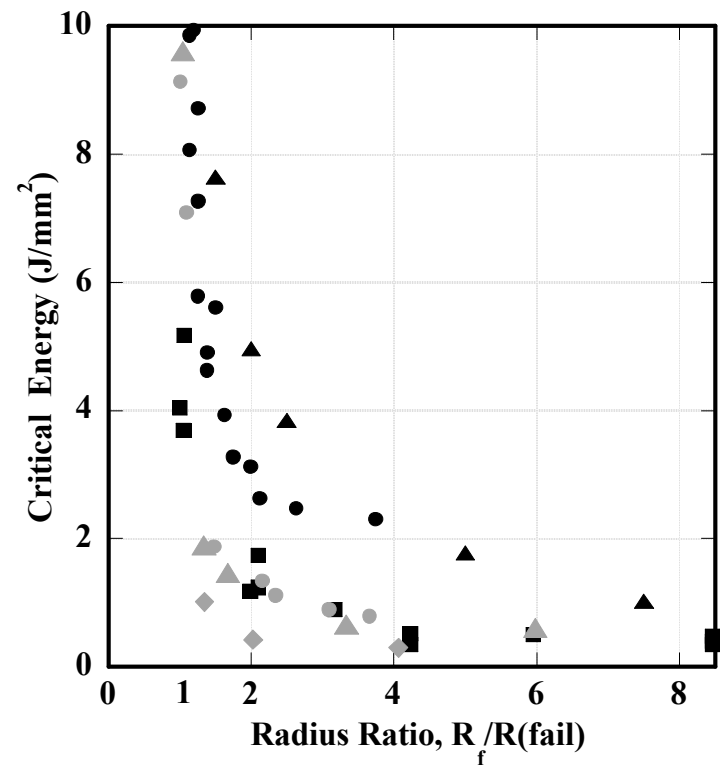

Figure 5. Critical energy versus radius ratio curve for flyer shots, where the flyer area is less than the explosive area. We get a P- $\tau$-type curve. The data is: TATB $1.80 \mathrm{~g} / \mathrm{cm}^{3}$ (black square), Comp B (black circle), pressed TNT $25 \mathrm{~mm}$ radius (black triangle) and $10 \mathrm{~mm}$ (gray triangle), LX-10 (gray diamond) and octol (gray circle)

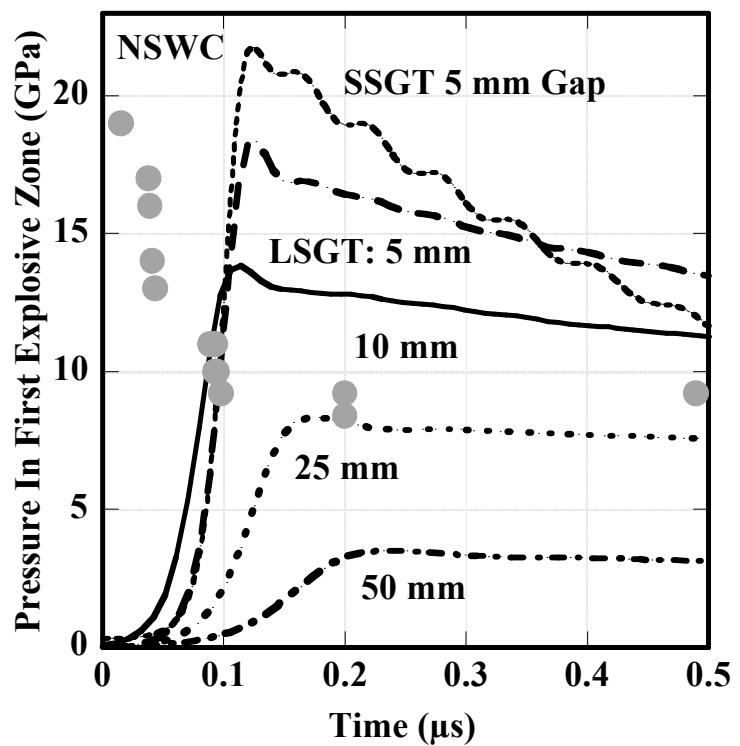

Figure 6. Calculated first-zone explosive pressures for $1.80 \mathrm{~g} / \mathrm{cm}^{3}$ TATB in the NSWC LSGT at four spacer thicknesses and one SSGT for comparison. The gray circles are the flyer-measured threshold P- $\tau$ points. 


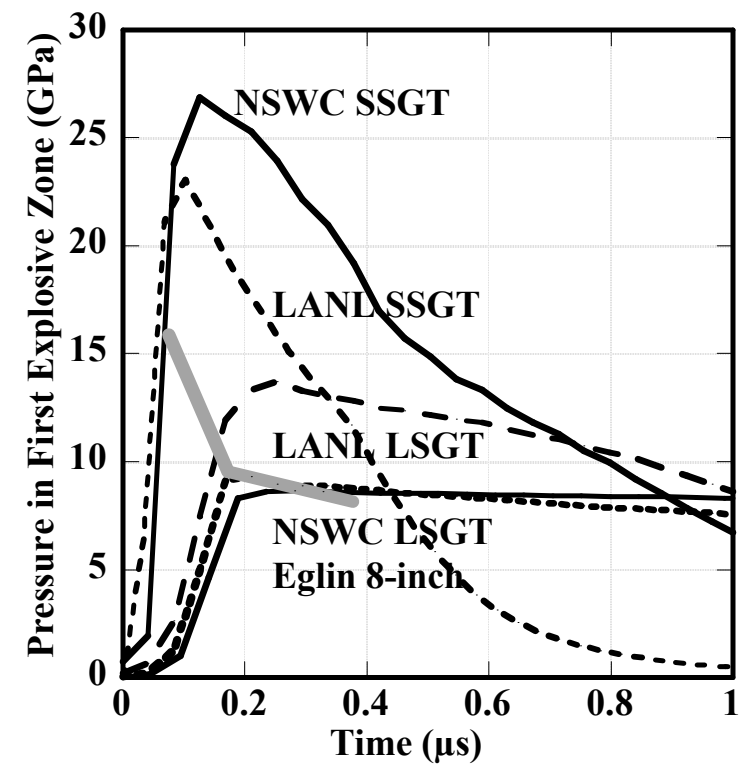

Figure 7. Calculated first-zone explosive 50\%-detonation pressures for $1.88-1.90 \mathrm{~g} / \mathrm{cm}^{3} \mathrm{LX}-17 / \mathrm{PBX} 9502$ for five gap tests. It shows that the rise time increases and the pressure decreases with the test size. The gray line is the integrated critical energy equal to $1 \mathrm{~J} / \mathrm{mm}^{2}$. 